\title{
Changing rates of genetic subtypes of Prader-Willi syndrome in the UK
}

\author{
Joyce E Whittington ${ }^{* 1}$, Jill V Butler ${ }^{1}$ and Anthony J Holland ${ }^{1}$ \\ ${ }^{1}$ Department of Psychiatry, Section of Developmental Psychiatry, University of Cambridge, Cambridge, UK
}

The genetically determined neurodevelopmental disorder, Prader-Willi syndrome (PWS), has two main genetic subtypes: a 15q11-q13 deletion affecting the paternally inherited chromosome 15 and chromosome 15 maternal uniparental disomy (mUPD) in which two maternal copies of chromosome 15 are inherited but no paternal copy. It has been accepted that these subtypes occur in approximately 70 and $25 \%$ of cases, respectively. This is the first report of a greater proportion (50\%) of those with PWS due to mUPD in children presently under 5 years living in the UK. Increasing maternal age at conception is likely to explain the changing proportions in this generation of mothers.

European Journal of Human Genetics (2007) 15, 127-130. doi:10.1038/sj.ejhg.5201716; published online 6 September 2006

Keywords: Prader-Willi syndrome; genetic subtypes; maternal age

\section{Background}

The genetically determined neurodevelopmental disorder, Prader-Willi syndrome (PWS), results from the absence of expression of one or more maternally-imprinted/paternally-expressed genes in the region 15q11-q13. There are two main genetic subtypes of PWS: a deletion of the PWS critical region q11-q13 of the paternally inherited chromosome 15 and maternal uniparental disomy (mUPD), in which two maternal copies of chromosome 15 are inherited but no paternal copy. PWS can also arise from unbalanced translocations involving the PWS region and from imprinting defects. Since reliable genetic testing for the syndrome became widely available approximately 15 years ago, the birth incidence rates of PWS have been revised downwards as a result of the findings from three separate studies, from one in 15000 to one in $22000-$ 25000 , based on an all-ages population study in a region of the $\mathrm{UK}^{1}{ }^{1}$ an age-censored population study in Flanders ${ }^{2}$ and a 3-year genetics register study in Australia. ${ }^{3}$

${ }^{*}$ Correspondence: Dr JE Whittington, Department of Psychiatry, University of Cambridge, Douglas House, 18b Trumpington Road, Cambridge CB2 2AH, UK.

Tel: + 4401223 746108; Fax: + 4401223 746122;

E-mail: jew1000@cam.ac.uk

Received 17 March 2006; revised 12 July 2006; accepted 27 July 2006; published online 6 September 2006
In the literature on PWS, proportions of cases in each of the genetic subtypes are usually given as (approximately) $70 \%$ deletion, $25-30 \%$ mUPD and 3-5\% other (translocations and IC defects). In the samples used in our population-based study to determine birth incidence rates, the proportions of the genetic subtypes found were similar to the above as shown in Table 1. In a subsequent extension of this population-based study, investigating psychiatric illness in adults with PWS (18 years or over) in the UK, there were 119 genetically confirmed adults with PWS among 156 people who volunteered for the study. Of these 119 , there were $70 \%$ with deletions, $27 \%$ with mUPD and $3.4 \%$ other.

What governs these proportions and can they ever change? Deletions, unbalanced translocations and imprinting defects appear to be random genetic accidents - there has been one report suggesting that paternal contact with hydrocarbons could be important, ${ }^{4}$ but this has never been supported. mUPD is hypothesised to result from 'trisomy rescue' of trisomy 15 caused by nondysjunction of maternal chromosomes, the paternal chromosome being discarded to give a viable foetus. In the literature, one of the early-documented differences between the two main genetic subtypes of PWS was maternal age, those with mUPD being born to older mothers. ${ }^{5}$ It is well known that 
older mothers give birth to babies with trisomies, as in Down's syndrome, more frequently than their younger counterparts. ${ }^{6,7}$ Census returns since 1976 show a relative increase in the numbers of mothers in older $(30+)$ age groups. ${ }^{8}$ A more recent source of genetic abnormalities may be assisted reproductive technologies, which were not available to an earlier generation of parents but were to the present generation and which are known to increase the rate of imprinted gene abnormalities. ${ }^{9}$

The present article evaluates some recent evidence that the proportions of genetic subtypes of PWS are changing, at least in the UK, and that the reason for this change is the trend for women to have their children later in life. The implications of this finding are also discussed.

\section{Materials and methods Participants}

The participants are 36 children aged under 5 years with PWS and their mothers all of whom are participating in a study of the early phenotype of PWS. All of these young children have genetically confirmed diagnoses of PWS.

\section{Recruitment}

For this study, potential participants are contacted by region of residence through the PWSA-UK. The response rate is currently as high as $79.6 \%$.

\section{Ascertainment}

Participants are visited in their homes by an experienced researcher who conducts an interview with the parent(s). At this visit, parents are asked for written confirmation of genetic subtype or for permission to write to the genetics clinic where the diagnosis was made. The mother's and baby's dates of birth and gestation period are also ascertained.

\section{Investigations}

(1) Proportions of PWS genetic subtypes in sample of under fives.

(2) Mother's age by genetic subtype.

(3) Birth order by genetic subtype in a previous population sample.

Table 1 Proportions of PWS genetic subtypes in recent birth incidence samples

\begin{tabular}{lccccc}
\hline Location & $\begin{array}{c}\text { Sample } \\
\text { total }\end{array}$ & $\begin{array}{c}\text { Sample } \\
\text { ascertained }\end{array}$ & $\begin{array}{c}\text { Deletion } \\
(\%)\end{array}$ & $\begin{array}{c}\text { UPD } \\
(\%)\end{array}$ & $\begin{array}{c}\text { Other } \\
(\%)\end{array}$ \\
\hline UK & 96 & 58 & 74 & 22 & 3 \\
Flanders & 78 & 73 & 69 & 19 & 5 \\
Australia & 30 & 24 & 70 & 10 & 0 \\
\hline
\end{tabular}

\section{Results}

(1) Of 36 children seen to date, 34 children had confirmed genetic subtype. Of these, there were 15 (44\%) with deletions, 17 (50\%) with mUPD and two (6\%) with IC mutations. Two have not yet been ascertained. The probability that this sample could have come from a population with the traditional proportions of deletion and MUPD cases (70 and 30\%) is given by $\chi^{2}=22.9$ (1d.f.), which is significant at the 0.001 level.

(2) Figure 1 shows the genetic subtype and mother's age at birth for 36 young PWS children seen to date. A comparison of means of mother's age at baby's birth for deletion and mUPD babies gives $t=-3.623, P=0.001$, effect size 1.3 .

(3) To examine the effect of maternal age further, we also re-visited data from our earlier population-based study. ${ }^{1}$ Maternal age was not recorded in that study but birth order was. We have therefore examined the relationship between genetic subtype and birth order as a proxy measure of maternal age. Frequencies of birth order for the genetic subtypes were as shown in Table 2. It was also noted at the time that four of the

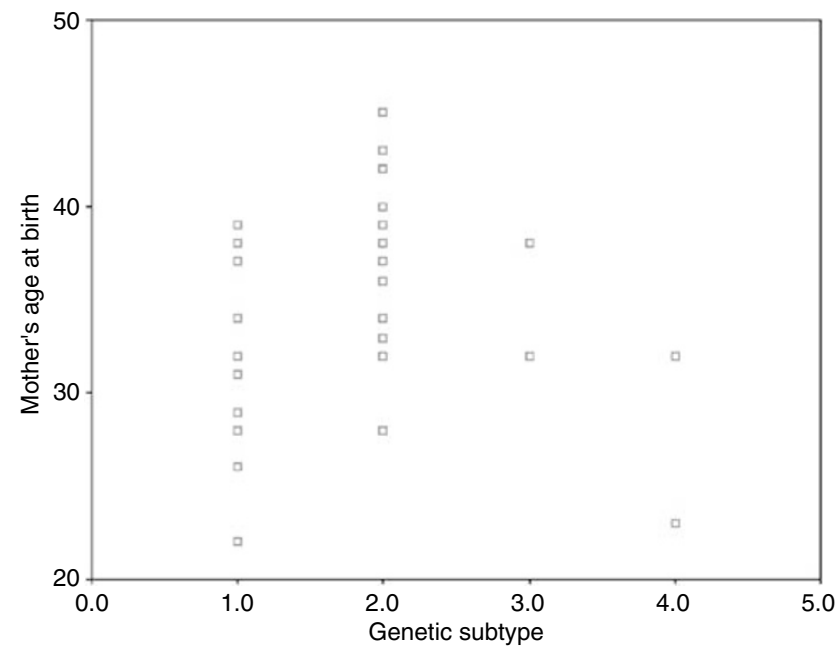

Figure 1 Age of mother at baby's birth by genetic subtype $(1=$ deletion, $2=$ mUPD, $3=\mathrm{IC}$ fault and $4=$ not yet ascertained $)$.

Table 2 Birth order of PWS genetic subtypes in a population study

\begin{tabular}{lcccc}
\hline Birth order & Deletion & UPD & Translocation & Imprinting center \\
\hline 1 & 16 & $2^{\mathrm{a}}$ & - & - \\
2 & 18 & 5 & - & - \\
3 & 6 & 2 & - & - \\
4 & 1 & 3 & 1 & 1 \\
\hline
\end{tabular}


UPD participants (aged 7, 13, 13 and 23) had adult/ much older siblings. As shown in Table 2, those with mUPD commonly had older siblings in comparison with those with PWS due to deletions. A statistical comparison of the birth order distributions gave $\chi^{2} 7.66$ (3 d.f.) sig. 0.055 (two sided): Fisher's exact test 6.465 sig. 0.069 (two sided).

\section{Discussion}

As noted in the Materials and methods, potential participants in our under fives study are contacted by region of residence through the PWSA-UK. The response rate is currently as high as $79.6 \%$. Observations on the proportions of genetic subtypes of PWS are therefore likely to be a true reflection of the actual proportions. The proportions of genetic subtypes we have found are significantly different from those of our own population-based studies and from others published in the literature. Fifty per cent have been found to have a chromosome 15 mUPD.

In this sample of mothers with young children with PWS, the usual difference in maternal ages between the two main subtypes of PWS is found (see Figure 1). Census returns for the period $1976-2002^{8}$ for the numbers of births to mothers in various age groups are shown in Figure 2 . The birth incidence estimates, ${ }^{1-3}$ referenced in the opening paragraph, give the risk of a PWS child as 1:22 000-1:25 000 live births. With the traditional estimate of the proportion of mUPD babies of $25-30 \%$, this gives a risk of 1:73000-1:100000 for an mUPD child. Robinson et al $^{10}$ show that the risk rises exponentially with mother's age, as in Down's syndrome, reaching 1:3400 for ages $40+$. A crude estimate of the effect of mother's

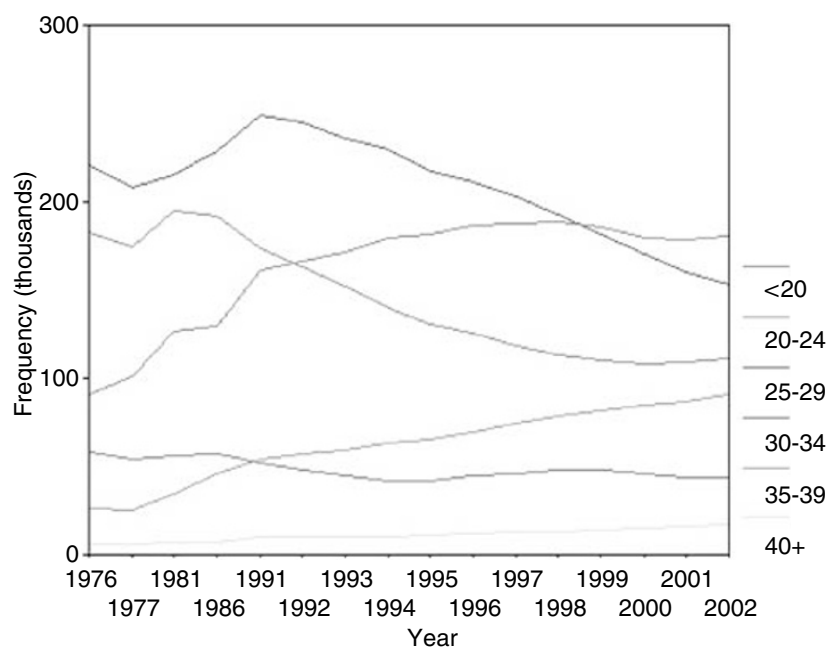

Figure 2 UK Census data for numbers of mothers in the age groups <20, 20-24, 25-29, 30-34, 35-39 and $40+$ for the period 1976-2002. age on mUPD prevalence can be calculated. Using the risk rates for mUPD from Robinson et $a l^{10}$ and the numbers of births from the census data for 1976 and 2002 for 5-year age groups, we find that six mUPD babies were expected in 1976 and 10 in 2002, an increase of 67\%. The total numbers of babies born in those years were 584300 and 596100 , so that the number of PWS babies expected (at $1: 25000)$ in the 2 years differs by at most one. These data support the hypothesis that the changing genetic subtype proportions are due to an increase in the numbers of mUPD babies because of the increasing proportions of older mothers.

Although we propose that maternal age is the most likely explanation of this observed increase in those with PWS due to mUPD, other possible explanations include: undiagnosed mUPD cases in older studies, sampling error in the infants study, some environmental variable causing genetic errors and, possibly, the consequence of assisted reproductive technologies, which were not available to an earlier generation of parents but were to this younger generation and which are known to increase the rate of imprinted gene abnormalities. ${ }^{9}$ Undiagnosed case is an unlikely explanation, as (i) most samples show overinclusion, in that non-PWS individuals are found in most volunteer 'PWS' samples and (ii) 'core' clinical criteria are common to both deletion and mUPD subtypes and are enough to warrant a suspicion of PWS. ${ }^{11}$ Sampling error is also unlikely: the PWSA-UK sent letters of invitation to all eligible members in all three UK studies previously mentioned, two of which resulted in samples with conventional proportions of genetic subtypes. As mentioned above, the response rate in the infants study is currently $79.6 \%$, so that even if all those not wishing to take part had children with PWS due to deletions, $39.8 \%$ of children with PWS in this group would have mUPD. The only environmental connection mentioned in the literature was a possible paternal involvement in the hydrocarbon industry, ${ }^{4}$ and this has never been corroborated. Assisted reproductive technologies were not involved in any of the infant sample.

The trend to more PWS mUPD births in the UK, which has an advanced economy and a trend to having families later in life, raises important issues. First, assuming that those with PWS due to deletions are not decreasing in numbers, we would expect a small increase in the birth incidence of PWS, given the increase in the proportion of those with mUPD. Second, those with mUPD have been shown to have specific mental health problems in later life and it will be important that appropriate services are there to meet this need. ${ }^{12}$ Third, older mothers may wish to be offered the option of genetic testing for PWS. Fourth, those with mUPD have different ability profiles compared with those with deletion PWS and others with intellectual disabilities $^{13}$ for which educational services should be prepared. 


\section{Acknowledgements}

The research studies referred to in this paper were supported by grants from the Baily Thomas Charitable Fund, the Health Foundation and the Wellcome Trust. We thank the PWSA-UK for help in contacting participants and the participants and their carers for taking part in the research.

\section{Ethics approval}

All three UK studies cited had ethics approval. The ethics committees concerned are:

Eastern MREC for the population and psychiatric studies.

Cambridge LREC for the under fives study.

\section{Competing interests}

None of the authors had competing interests.

\section{References}

1 Whittington JE, Holland AJ, Webb T, Butler JV, Clarke DJ, Boer H: Population prevalence and estimated birth incidence and mortality rate for people with Prader-Willi syndrome in one UK Health Region. J Med Genet 2001; 38: 792-798.

2 Vogels A, Van Den Ende J, Keymolen K et al: Minimum prevalence, birth incidence and cause of death for Prader-Willi syndrome in Flanders. Eur J Hum Genet 2004; 12: $238-240$

3 Smith A, Egan J, Ridley G et al: Birth prevalence of Prader-Willi syndrome in Australia. Arch Dis Child 2003; 88: 263-264.

4 Akefeldt A, Anvret M, Grandell U, Nordlinder R, Gillberg C: Parental exposure to hydrocarbons in Prader-Willi syndrome. Dev Med Child Neurol 1995; 37: 1101-1109.

5 Cassidy SB, Forsythe M, Heeger S et al: Comparison of phenotype between patients with Prader-Willi syndrome due to deletion $15 q$ and uniparental disomy 15. Am J Med Genet 1997; 68: 433-440.

6 Warburton D: Biological aging and the etiology of aneuploidy. Cytogenet Genome Res 2005; 111: 266-272.

7 Sherman SL, Freeman SB, Allen EG, Lamb NE: Risk factors for nondisjunction of trisomy 21. Cytogenet Genome Res 2005; 111: 273-280.

8 Health Statistics Quarterly, vol. 20. Office for National Statistics: London, 2003, p 51.

9 Clayton-Smith J: Genomic imprinting as a cause of disease. BM 2003; 327: 1121-1122.

10 Robinson WP, Langlois S, Schuffenhauer S et al: Cytogenetic and age-dependent risk factors associated with uniparental disomy 15. Prenat Diagn 1996; 16: 837-844.

11 Whittington JE, Holland AJ, Webb T, Butler JV, Clarke DJ, Boer H: Relationship between clinical and genetic diagnosis of PraderWilli syndrome. J Med Genet 2002; 39: 926-932.

12 Boer H, Holland AJ, Whittington JE, Butler JV, Webb T, Clarke DJ: Psychotic illness in people with Prader-Willi syndrome due to chromosome 15 maternal uniparental disomy. Lancet 2002; 359: $135-136$.

13 Whittington JE, Holland AJ, Webb T, Butler JV, Clarke DJ, Boer H: Cognitive abilities and genotype in a population-based sample of people with Prader-Willi syndrome. J Intellect Disabil Res 2004; 48: $172-187$. 